\title{
The Effects of Eicosapentaenoic Acid-Fortified Food on Inflammatory Markers in Healthy Subjects-A Randomized, Placebo-Controlled, Double-Blind Study
}

\author{
Shuntaro FujIOKA ${ }^{1}$, Kei HAMAZAKI ${ }^{1}$, Miho ITOMURA ${ }^{1}$, Mingming HuAN ${ }^{1}$, Hiroto NishizAWA ${ }^{1}$, \\ Shigeki SAWAZAKI ${ }^{2}$, Isao KITAJIMA ${ }^{3}$ and Tomohito HAMAZAKI ${ }^{1, *}$ \\ ${ }^{1}$ Division of Clinical Application, Department of Clinical Sciences, Institute of Natural Medicine, \\ University of Toyama, Toyama 930-0194, Japan \\ ${ }^{2}$ First Department of Internal Medicine, and ${ }^{3}$ Laboratory Medicine, \\ University of Toyama School of Medicine, Toyama 930-0194, Japan
}

(Received September 12, 2005)

\begin{abstract}
Summary Epidemiological studies showed that habitual fish intakes were associated with lower blood inflammatory markers. In the present study the effects of a fish oil-containing food on inflammatory markers were investigated in healthy, mostly middle-aged subjects ( 59 men and 82 women) with normal to mildly elevated triglyceride levels. Study subjects were randomly allocated to two groups in a double-blind manner; one group ingested an eicosapentaenoic acid (EPA)-rich fish oil-fortified drink (0.60 g EPA $+0.26 \mathrm{~g}$ docosahexaenoic acid/d, EPA group, $n=68$ ) for $12 \mathrm{wk}$. The rest of the subjects took a placebo (control group, $n=73$ ). Plasma levels of high sensitivity C-reactive protein (hs-CRP) and soluble tumor necrosis factor-receptors 1 and 2 (sTNF-Rs 1 and 2) were measured at the start and end of intervention. EPA concentrations in the total RBC phospholipid fraction significantly increased by $79 \%$ in the EPA group at the end of the study, and they changed very little in the control group $(+0.68 \%)$. The inflammatory markers did not change in either group. It is likely that fish oil does not change hs-CRP or sTNF-Rs 1 or 2 in subjects without active inflammation.
\end{abstract}

Key Words high sensitivity C-reactive protein, soluble tumor necrosis factor-receptors, eicosapentaenoic acid, fish oil

Chronic low-grade inflammation seems to play an important role in the initiation and progression of atherosclerosis (1). High serum levels of C-reactive protein (CRP) measured by highly sensitive assays have been shown to be an increased risk for myocardial infarction in apparently healthy subjects $(2,3)$, and it has been suggested that those levels be measured in coronary risk assessment (4).

Fish oils have anti-inflammatory and also anti-atherosclerotic effects (5), which implies the possibility that fish oils may reduce high sensitivity (hs)-CRP levels. Actually it was found in a cross-sectional study that docosahexaenoic acid (DHA) concentrations in granulocytes had inverse associations with hs-CRP in serum (6). Besides, a prospective cohort investigation with 859 US health professionals showed that habitual intakes of fish were significantly associated with lower levels of inflammatory markers such as soluble tumor necrosis factor receptors 1 and 2 (sTNF-Rs 1 and 2), although CRP only tended to be associated with fish consumption (7). Recently total $n-3$ fatty acid intakes were shown to have an inverse relation with hs-CRP but not with sTNF-R2 in a cross sectional study of 727 women from the Nurses' Health Study I cohort (8).

\footnotetext{
* To whom correspondence should be addressed.

E-mail: hamazaki@inm.u-toyama.ac.jp
}

However, the results from five of the six intervention studies recently performed in subjects who did not suffer from active inflammation do not support the effects of fish oils on hs-CRP (Table 1). Ciubotaru et al. (10) administered $14 \mathrm{~g}$ or $7 \mathrm{~g}$ of fish oil or safflower oil to postmenopausal women on hormone replacement therapy for $5 \mathrm{wk}$. They found that fish oil supplementation significantly decreased CRP compared to the safflower oil-supplemented control group, with a greater effect in the low fish oil than high fish oil groups. This was the only intervention study that showed active effects of fish oil on hs-CRP.

In the present study we investigated whether fish oil was able to decrease hs-CRP and also sTNF-Rs 1 and 2 in a double-blind test with a larger number $(n=141)$ of apparently healthy subjects. The original purpose of the present study was to investigate the effect of eicosapentaenoic acid (EPA)-fortified food on serum triglyceride levels, but here we mainly discuss changes in inflammatory markers.

\section{MATERIALS AND METHODS}

Subjects. One hundred and sixty-one employees were recruited as subjects of the present study from 11 local companies located in Toyama Prefecture. Those people were not eligible for the present study who were prescribed for hyperlipidemia or used food supplements 


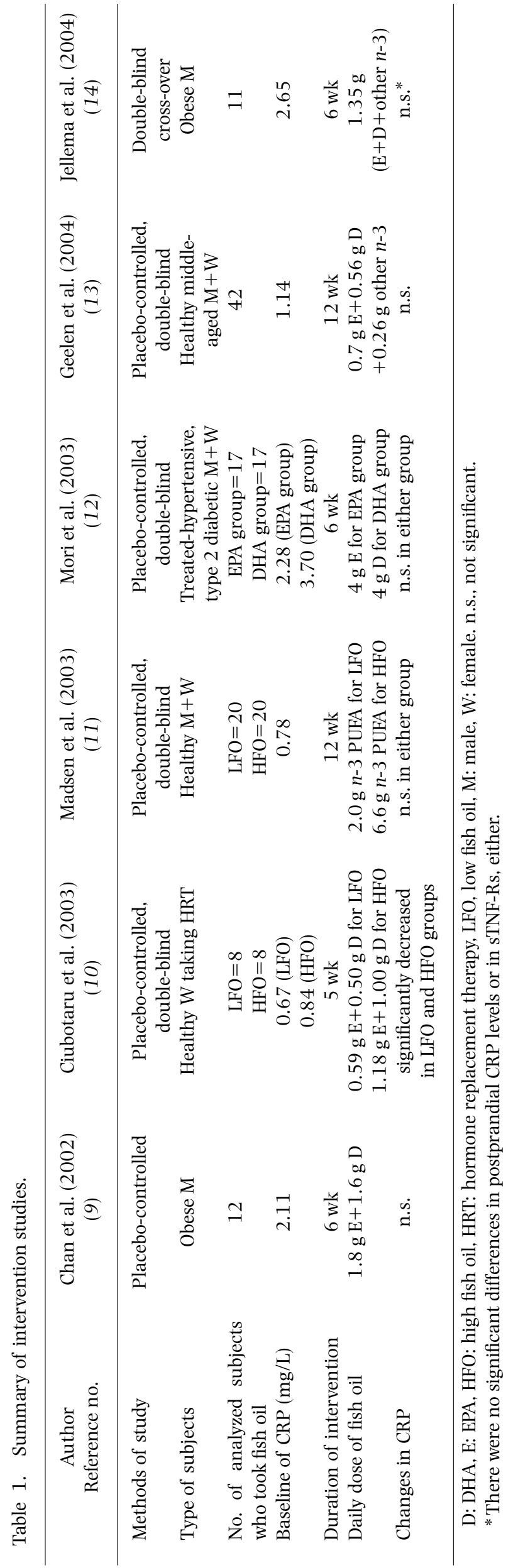

or hormones which might influence their lipid profile during the previous $3 \mathrm{mo}$. Subjects were asked to come to their own offices early in the morning, and their blood samples were taken after at least $10 \mathrm{~h}$ of fasting. We deleted 4 subjects whose triglyceride levels were over $3.40 \mathrm{mmol} / \mathrm{L}$. The present study was approved by the ethics committee of Toyama Medical and Pharmaceutical University (University of Toyama at present), and written informed consent was obtained from each participant.

Study design. One hundred and fifty-seven subjects were stratified by gender, age and triglyceride levels, and then randomly allocated either to an eicosapentaenoic acid (EPA) (33 males and 48 females) group or a control (30 males and 46 females) group in a double-blind manner. Study subjects were instructed to take test materials (see below) once a day at any time of the day. All subjects were asked to maintain their body weight and physical activity levels, and to consume their habitual diet during the study. They were also asked to check their calendars when they took test materials, and to submit those calendars to us every month. At the start and $12 \mathrm{wk}$ after starting the test materials, blood samples were taken in the early morning after at least $10 \mathrm{~h}$ of fasting. At blood sampling points, food intake was calculated with a semi-quantitative food-frequency questionnaire and a food calculation software program, Eiyoukun 3.0 (Kenpakusha Co. Ltd., Tokyo). To assess nutrients, study subjects were asked how often on average they ate a portion size of each food during the $4 \mathrm{wk}$ prior to the two checkpoints. Correlation between the estimated daily EPA intake from the questionnaire and its concentrations in the total phospholipid fraction in red blood cells (RBC PL) was about 0.4 in over 400 subjects (data not published).

Test foods (active and placebo) were two kinds of soymilk-based drink described previously (15) (Table 2). One pack $(125 \mathrm{~mL})$ of the active food contained $2.2 \mathrm{~g}$ of fish oil, of which $28 \%$ and $12 \%$ were EPA $(0.60 \mathrm{~g} /$ pack $)$ and DHA $(0.26 \mathrm{~g} /$ pack $)$, respectively. The other kind of pack (control material) contained $2.2 \mathrm{~g}$ of olive oil instead of fish oil.

Blood samples were collected between 8 and 9 a.m. Serum concentrations of triglycerides, low-density lipoprotein (LDL)-cholesterol and high-density lipoprotein (HDL)-cholesterol were measured enzymatically (16). Remnant-like particle (RLP)-cholesterol was first separated by immunoaffinity chromatography (15) and measured enzymatically. Plasma samples obtained from EDTA-anticoagulated blood samples were frozen at $-80^{\circ} \mathrm{C}$ until inflammatory marker analysis. Packed RBCs were obtained from EDTA-anticoagulated blood, washed twice with saline, supplemented with butylated hydroxytoluene $(0.05 \mathrm{mg} / \mathrm{mL})$, and frozen at $-80^{\circ} \mathrm{C}$ until fatty acid analysis. The fatty acid composition of RBC PL was determined as written elsewhere (17). Briefly, the total lipids were extracted by the method of Bligh and Dyer; the total phospholipids fraction was separated by thin-layer chromatography; after transmethylation with HCl-methanol, the fatty acid compo- 
Table 2. Composition of the two kinds of soybean milk (125 mL/pack).

\begin{tabular}{lll}
\hline & \multicolumn{2}{c}{ Group } \\
\cline { 2 - 3 } & \multicolumn{2}{c}{ Control } \\
\hline Energy & 73 & EPA \\
Protein & 2.1 & 74 \\
Carbohydrate & 6.9 & 2.1 \\
Fat & $4.1 \quad(100 \%)$ & $4.2 \quad(100 \%)$ \\
$14: 0$ & $\mathrm{ND}$ & $0.14(3 \%)$ \\
$16: 0$ & $0.36(8 \%)$ & $0.40(10 \%)$ \\
$16: 1$ & $0.02(0.4 \%)$ & $0.26(6 \%)$ \\
$18: 0$ & $0.11(3 \%)$ & $0.17(4 \%)$ \\
$18: 1$ & $2.0(49 \%)$ & $0.54(13 \%)$ \\
$18: 2$ & $0.85(21 \%)$ & $0.72(17 \%)$ \\
$18: 3$ & $0.11(3 \%)$ & $0.10(3 \%)$ \\
EPA & ND & $0.60(14 \%)$ \\
DHA & ND & $0.26(6 \%)$ \\
\hline
\end{tabular}

Subjects ingested one pack of soybean milk/d for $12 \mathrm{wk}$. The unit of nutrients is g/pack except for energy (kcal/ pack).

ND: not detected.

sition was analyzed by gas chromatography (GC14A Shimadzu Corporation, Kyoto) with a capillary column DB-225 (0.25 mm, $30 \mathrm{~m}$ length id, $0.25 \mu \mathrm{m}$; J\&W Scientific, Folsom, CA). Hs-CRP was measured by a latexenhanced assay (18) with a BN nephelometer (Dade Behring Marburg GmbH, Marburg, Germany). When hs-CRP levels were below the detection limits $(0.039 \mathrm{mg} / \mathrm{L})$, the mean value between null and the detection limits was adopted. sTNF-R 1 and sTNF-R 2 concentrations were analyzed by an enzyme-linked immunosorbent assay (R\&D Systems, Inc., Minneapolis, $\mathrm{MN})$. Coefficients of variance of hs-CRP assay were below 5\% for both inter- and intra-assays. Those of STNF-R 1 were $11 \%$ and $8.7 \%$ for inter- and intraassay; those of sTNF-R 2 were $14 \%$ and $6.0 \%$, for interand intra-assay, respectively.

Statistical analysis. Results are expressed as means \pm SD. We analyzed fatty acid composition parametrically (the paired $t$-test for intra-group comparison and analysis of covariance for inter-group comparison). Because of the skewed distribution of inflammatory markers, they were log-transformed for analyses. Those data are expressed as geometric means $(-1 \mathrm{SD},+1 \mathrm{SD})$. Correlations were analyzed by the least square method. Stat View-J 5.0 (Abacus Concepts Inc., Berkeley, CA) was used for statistical analyses.

\section{RESULTS}

Four subjects in the EPA group and one in the control group suffered from diarrhea, and they discontinued taking test foods. During the study period four females became pregnant, and they were all deleted from the study. Another 7 subjects dropped out of the study because of personal reasons. We, therefore, analyzed the remaining 141 subjects. Their characteristics are
Table 3. Baseline characteristics of randomized subjects.

\begin{tabular}{lcc}
\hline \multirow{2}{*}{ Baseline characteristics } & \multicolumn{2}{c}{ Group } \\
\cline { 2 - 3 } & Control & EPA \\
\hline Number of subjects & 73 & 68 \\
Men/women & $30 / 43$ & $29 / 39$ \\
Hypertensive & 13 & 13 \\
Smoking & 29 & 27 \\
Age & $37.0 \pm 11.5$ & $38.8 \pm 11.6$ \\
BMI & $22.0 \pm 2.7$ & $22.2 \pm 3.3$ \\
\hline
\end{tabular}

There were no significant differences in baseline values between the two groups.

Table 4. Daily food intake of study subjects.

\begin{tabular}{lcc}
\hline & \multicolumn{2}{c}{ Group } \\
\cline { 2 - 3 } & Control & EPA \\
\hline Energy & $1881 \pm 661$ & $1964 \pm 779$ \\
Protein & $91.0 \pm 32.3$ & $95.8 \pm 56.2$ \\
Carbohydrate & $268 \pm 104$ & $285 \pm 126$ \\
Fat & $49.4 \pm 20.3$ & $49.0 \pm 24.8$ \\
DHA & $0.76 \pm 0.55$ & $0.78 \pm 0.59$ \\
EPA & $0.46 \pm 0.35$ & $0.47 \pm 0.38$ \\
$20: 4$ & $0.16 \pm 0.08$ & $0.16 \pm 0.10$ \\
$n-3$ & $2.79 \pm 1.70$ & $2.67 \pm 1.43$ \\
$n-6$ & $8.28 \pm 5.37$ & $7.29 \pm 3.32$ \\
\hline
\end{tabular}

The unit of nutrients is $\mathrm{g} / \mathrm{d}$ except for energy $(\mathrm{kcal} / \mathrm{d})$. Values did not contain any nutrients contained in the test foods.

There were no significant differences between the two groups in any items.

Table 5. Change in the fatty acid composition (\%) in RBC PL.

\begin{tabular}{|c|c|c|c|c|}
\hline \multirow{3}{*}{ Fatty acid } & \multicolumn{4}{|c|}{ Group } \\
\hline & \multicolumn{2}{|c|}{ Control } & \multicolumn{2}{|c|}{ EPA } \\
\hline & Start & End & Start & End \\
\hline 16:0 & $23.6 \pm 2.7$ & $24.0 \pm 2.0$ & $24.3 \pm 2.1$ & $24.4 \pm 1.6$ \\
\hline 18:0 & $14.5 \pm 1.9$ & $14.9 \pm 2.4$ & $14.2 \pm 1.6$ & $15.5 \pm 2.9$ \\
\hline $18: 1 n-9$ & $12.7 \pm 0.8$ & $12.9 \pm 0.9$ & $12.9 \pm 0.7$ & $12.6 \pm 1.0$ \\
\hline $18: 2 n-6$ & $9.0 \pm 1.2$ & $9.2 \pm 1.2$ & $9.2 \pm 1.1$ & $8.7 \pm 8.7$ \\
\hline $20: 4 n-6$ & $10.1 \pm 1.3$ & $10.5 \pm 1.3$ & $9.9 \pm 1.1$ & $9.1 \pm 1.1^{* *}$ \\
\hline $20: 5 n-3$ & $1.5 \pm 0.6$ & $1.5 \pm 0.6$ & $1.4 \pm 0.5$ & $2.5 \pm 0.7^{* *}$ \\
\hline $22: 5 n-3$ & $1.8 \pm 0.4$ & $1.8 \pm 0.3$ & $1.8 \pm 0.3$ & $2.3 \pm 0.3^{* *}$ \\
\hline $22: 6 n-3$ & $6.0 \pm 1.0$ & $6.2 \pm 1.1$ & $5.9 \pm 1.0$ & $6.2 \pm 0.9$ \\
\hline
\end{tabular}

There were no significant differences in baseline values between the two groups in any fatty acids. ${ }^{* *} p<0.001$ (ANCOVA).

shown in Table 3.

The mean intake of macronutrients and some fatty acids were calculated from two food questionnaires performed at the start and end of the study. Those values 
Table 6. Change in the serum levels of inflammation markers.

\begin{tabular}{lccccc}
\hline & \multicolumn{2}{c}{ Control } & & \multicolumn{2}{c}{ EPA } \\
\cline { 2 - 3 } \cline { 5 - 6 } & Week 0 & Week 12 & & Week 0 & Week 12 \\
\hline hs-CRP (mg/L) & $0.32(0.11,0.89)$ & $0.28(0.09,0.86)$ & & $0.33(0.09,1.21)$ & $0.25(0.07,0.87)$ \\
STNF-R 1 (ng/mL) & $1.09(0.86,1.38)$ & $1.06(0.88,1.27)$ & & $1.08(0.87,1.35)$ & $1.04(0.87,1.25)$ \\
STNF-R 2 (ng/mL) & $1.67(1.31,2.13)$ & $1.58(1.22,2.05)$ & & $1.75(1.36,2.24)$ & $1.55(1.21,1.99)$ \\
\hline
\end{tabular}

There were no significant differences in baseline values between the two groups.

There were no significant inter- or intra-group differences.

Table 7. Change in serum lipid levels $(\mathrm{mmol} / \mathrm{L})$.

\begin{tabular}{|c|c|c|c|c|}
\hline & \multicolumn{2}{|c|}{ Control group } & \multicolumn{2}{|c|}{ EPA group } \\
\hline & Week 0 & Week 12 & Week 0 & Week 12 \\
\hline Triglycerides & $0.98 \pm 0.54$ & $1.04 \pm 0.62$ & $1.08 \pm 0.68$ & $1.05 \pm 0.68$ \\
\hline LDL-cholesterol & $2.94 \pm 0.75$ & $2.86 \pm 0.67$ & $2.83 \pm 0.62$ & $2.81 \pm 0.62$ \\
\hline HDL-cholesterol & $1.50 \pm 0.34$ & $1.55 \pm 0.34$ & $1.44 \pm 0.31$ & $1.52 \pm 0.34$ \\
\hline RLP-cholesterol & $0.116 \pm 0.077$ & $0.116 \pm 0.077$ & $0.126 \pm 0.103$ & $0.108 \pm 0.062$ \\
\hline
\end{tabular}

There were no significant differences in baseline values between the two groups.

There were no significant inter- or intra-group differences.

did not differ significantly between the two groups (Table 4). Values in Table 4 did not contain any nutrients contained in the test foods. The compliance of test foods was $88 \%$ and $86 \%$ on average in the EPA and control groups, respectively, and not significantly different between groups.

EPA concentrations in RBC PL significantly increased in the EPA group $(+79 \%)$, but not in the control group during the study $(+0.68 \%)$. Changes in the fatty acid composition are shown in Table 5. Table 6 shows changes over time of hs-CRP, and sTNF-Rs 1 and 2 . There were no significant changes in those inflammatory parameters either in the EPA group or in the control group. Serum concentrations of the other lipids did not change significantly in the EPA group compared with the control group (Table 7).

The $n-3$ fatty acid dose used in the present study might be too low to affect inflammatory markers. We, therefore, calculated correlations between changes in EPA concentrations in RBC PL and those in hs-CRP in the EPA group. There was no correlation $(p=0.66)$. It was also the case for sTNF-Rs 1 and $2(p=0.64$ and 0.44 , respectively). There is a possibility that if we had used subjects whose baseline CRP values were relatively high, we might have obtained significant results. We recalculated the effects of EPA with the highest 19 subjects whose baseline CRP levels were more than $1.0 \mathrm{mg} /$ L. There were no significant differences between the EPA $(n=13)$ and control $(n=6)$ groups at all $(p=0.95)$. It was also the case for those whose baseline STNF-R 1 levels were more than $1.1 \mathrm{ng} / \mathrm{mL}$ (30 and 31 in the EPA and control groups, respectively, $p=0.33$ ), and those whose baseline sTNF-R 2 levels were more than $1.7 \mathrm{ng} /$ $\mathrm{mL}$ (36 and 31 in the EPA and control groups, respectively, $p=0.82$ ).

\section{DISCUSSION}

In the present study, hs-CRP did not change over time in either of the two groups. Our dose of fish oil $(\mathrm{EPA}+\mathrm{DHA}=0.86 \mathrm{~g} / \mathrm{d})$ was relatively small, but this dose was equal to that used in the GISSI study, in which sudden cardiac death was reduced by $45 \%$ (19). In fact, our dose significantly increased EPA concentrations by about $80 \%$ in the EPA group (see Table 5). Moreover, the scale of the present trial in terms of number of subjects and intervention periods was larger than in any previous intervention study investigating the effect of $n$ 3 fatty acids on hs-CRP levels (see Table 1). There were no correlations between EPA concentrations in RBC PL and inflammation markers at all. Taken together, it is unlikely that our dose was too low to detect the effects of $n-3$ fatty acids on inflammatory markers.

The average baseline levels of hs-CRP of our study subjects were 0.32 and 0.33 in the control and EPA groups, respectively. These values were much lower than the baseline levels of previously published studies (Table 1). However, there were no effects of fish oil even in the high CRP (more than $1.0 \mathrm{mg} / \mathrm{L}$ ) subgroups as shown in "Results". It might be possible to reduce inflammatory markers in patients with active inflammation as reported by Sundrarjun et al. (20), who used subjects with active rheumatoid arthritis. The baseline values of CRP in their rheumatoid arthritis patients in the fish oil group were $51 \mathrm{mg} / \mathrm{L}$ and much higher than those shown in Table 1.

No significant effects on sTNF-R 1 or 2 were observed. Our observation was different from the results of a cross-sectional study reported by Pischon et al. (7), but similar to those of an intervention study reported by Jellema et al. (14), who could not observe any signifi- 
cant decrease in sTNF-R 1 or 2 after administration of $1.35 \mathrm{~g}$ of $n-3$ highly unsaturated fatty acids to obese subjects.

Recently we reported that the test food reduced the serum levels of triglycerides and RLP-cholesterol (15). The reasons why there were no significant differences in those lipid levels between the EPA and control groups were not clear. However, the mean basal levels in subjects in the previous study (15) were rather high (triglycerides: 1.65-1.83 mmol/L; RLP-cholesterol: 0.13$0.15 \mathrm{mmol} / \mathrm{L}$ ) compared with the present study (see Table 7). This might be one of the reasons.

In conclusion, it is likely that fish oils do not change inflammatory parameters such as hs-CRP and sTNF-Rs 1 and 2 in subjects without active inflammation.

\section{Acknowledgments}

This work was partly funded by Fine Chemical Department, Nippon Suisan Kaisha, Ltd. We are grateful to Ms. Hiroko Hamatani and Ms. Shizuko Takebe for their excellent technical assistance.

\section{REFERENCES}

1) Ross R. 1999. Atherosclerosis-an inflammatory disease. N Engl J Med 340: 115-126.

2) Ridker PM. 1997. Inflammation, aspirin, and the risk of cardiovascular disease in apparently healthy men. New Engl J Med 336: 973-979.

3) Koenig W, Sund M, Frohlich M, Fischer HG, Lowel H, Doring A, Hutchinson WL, Pepys MB. 1999. C-Reactive protein, a sensitive marker of inflammation, predicts future risk of coronary heart disease in initially healthy middle-aged men: results from the MONICA (Monitoring Trends and Determinants in Cardiovascular Disease) Augsburg Cohort Study, 1984 to 1992. Circulation 99: $237-242$.

4) Ridker PM. 2004. High-sensitivity C-reactive protein, inflammation, and cardiovascular risk: from concept to clinical practice to clinical benefit. Am Heart J 148: S19-S26.

5) Yaqoob P, Calder PC. 2003. N-3 polyunsaturated fatty acids and inflammation in the arterial wall. Eur J Med Res 8: 337-354.

6) Madsen T, Skou HA, Hansen VE, Fog L, Christensen JH, Toft E, Schmidt EB. 2001. C-Reactive protein, dietary $n$ 3 fatty acids, and the extent of coronary artery disease. Am J Cardiol 88: 1139-1142.

7) Pischon T, Hankinson SE, Hotamisligil GS, Rifai N, Willett WC, Rimm EB. 2003. Habitual dietary intake of $n-3$ and $n-6$ fatty acids in relation to inflammatory markers among US men and women. Circulation 108: 155-160.

8) Lopez-Garcia E, Schulze MB, Manson JE, Meigs JB, Albert CM, Rifai N, Willett WC, Hu FB. 2004. Consumption of $(n-3)$ fatty acids is related to plasma biomarkers of inflammation and endothelial activation in women. J Nutr 134: 1806-1811.

9) Chan DC, Watts GF, Barrett PH, Beilin LJ, Mori TA.
2002. Effect of atorvastatin and fish oil on plasma highsensitivity C-reactive protein concentrations in individuals with visceral obesity. Clin Chem 48: 877-883.

10) Ciubotaru I, Lee YS, Wander RC. 2003. Dietary fish oil decreases C-reactive protein, interleukin-6, and triacylglycerol to HDL-cholesterol ratio in postmenopausal women on HRT. J Nutr Biochem 14: 513-521.

11) Madsen T, Christensen JH, Blom M, Schmidt EB. 2003. The effect of dietary n-3 fatty acids on serum concentrations of C-reactive protein: a dose-response study. $\mathrm{Br} \mathrm{J}$ Nutr 89: 517-522.

12) Mori TA, Woodman RJ, Burke V, Puddey IB, Croft KD, Beilin LJ. 2003. Effect of eicosapentaenoic acid and docosahexaenoic acid on oxidative stress and inflammatory markers in treated-hypertensive type 2 diabetic subjects. Free Radic Biol Med 35: 772-781.

13) Geelen A, Brouwer IA, Schouten EG, Kluft C, Katan MB, Zock PL. 2004. Intake of $n-3$ fatty acids from fish does not lower serum concentrations of C-reactive protein in healthy subjects. Eur J Clin Nutr 58: 1440-1442.

14) Jellema A, Plat J, Mensink RP. 2004. Weight reduction, but not a moderate intake of fish oil, lowers concentrations of inflammatory markers and PAI-1 antigen in obese men during the fasting and postprandial state. Eur J Clin Invest 34: 766-773.

15) Hamazaki $K$, Itomura $M$, Huan $M$, Nishizawa $H$, Watanabe S, Hamazaki T, Sawazaki S, Terasawa T, Nakajima S, Terano T, Hata Y, Fujishiro S. 2003. n-3 Long chain FA decrease serum levels of TG and remnant-like particle-cholesterol in humans. Lipids $\mathbf{3 8}$ : 353-358.

16) Tamaoku K, Ueno K, Akiura K, Ohkura Y. 1982. New water-soluble hydrogen donors for the enzymatic photometric determination of hydrogen peroxide. $n$-Ethyl- $n$ (2-hydoroxy-3-sulfopropyl) aniline derivatives. Chem Pharm Bull 30: 2492-2497.

17) Hamazaki $K$, Itomura $M$, Huan $M$, Nishizawa $H$, Sawazaki S, Tanouchi M, Watanabe S, Hamazaki T, Terasawa K, Yazawa K. 2005. The effect of $\omega$-3 fatty acid-containing phospholipids on blood catecholamine concentrations in healthy volunteers: a randomized, placebo-controlled, double-blind trial. Nutrition 21: 705-710.

18) Macy EM, Hayes TE, Tracy RP. 1997. Variability in the measurement of C-reactive protein in healthy subjects: implications for reference intervals and epidemiological applications. Clin Chem 43: 52-58.

19) GISSI-Prevenzione Intervention. 1999. Dietary supplementation with $n-3$ polyunsaturated fatty acids and vitamin $\mathrm{E}$ after myocardial infarction: results of the GISSI-Prevenzione trial. Gruppo Italiano per lo Studio della Sopravvivenza nell'Infarto miocardico. Lancet 354: 447-455.

20) Sundrarjun T, Komindr S, Archararit N, Dahlan W, Puchaiwatananon O, Angthararak S, Udomsuppayakul U, Chuncharunee S. 2004. Effects of $n$-3 fatty acids on serum interleukin-6, tumour necrosis factor-alpha and soluble tumour necrosis factor receptor p55 in active rheumatoid arthritis. J Int Med Res 32: 443-454. 